\title{
El Derecho Cooperativo y la Globalizacion
}

\author{
Dante Cracogna \\ Universidad de Buenos Aires
}

\section{Globalización y cooperativismo}

La globalización ha producido un fuerte impacto cuyos múltiples efectos se aprecian en todos los órdenes de la actividad económica, social y política. La literatura contemporánea da cuenta de ello a través de una abundante producción, generalmente controversial puesto que suele orientarse a señalar presuntos beneficios exclusivamente o bien se concentra en formular severas críticas. La globalización es vista como una bendición por la que hay que estar agradecido o como una maldición de los tiempos modernos que azota a la humanidad como un implacable castigo de Dios. La receta para hacerle frente consiste, pues, según cada enfoque, en aprovechar sus preciosas ventajas o en asumir resignadamente sus inevitables consecuencias.

Con relación a las cooperativas y la globalización suele ocurrir algo parecido y son frecuentes las polémicas al respecto. El punto de vista que se adopta suele consistir en un enjuiciamiento de la globalización, observando el proceso desde una perspectiva externa como si se tratara de un fenómeno ajeno, y del cual resulta una condena o una aprobación. En realidad pocas son las veces en que se analiza a la globalización desde adentro, considerando al movimiento cooperativo como una parte de ella a fin de entender con verdadero realismo el sentido de ese proceso y el papel de las cooperativas como integrantes de ese contexto.

Existen, sin embargo, algunos enfoques esclarecedores que permiten revalorar la ubicación y el rol de las cooperativas en el mundo globalizado con miras a su mejor comprensión valiéndose para ello de los indicadores que exhibe el mundo contemporáneo y que han sido detectados tanto por los observadores ajenos como por los analistas del propio movimiento cooperativo. Entre ellos merece destacarse, casi 
como verdadera literatura de anticipación, el estudio del canadiense Alexander F. Laidlaw titulado Las cooperativas en año 2000, que fuera presentado como documento central en el XXVII Congreso de la Alianza Cooperativa Internacional $(\mathrm{ACl})$ realizado en Moscú en $1980^{1}$. La característica central de este estudio consiste en que realiza una prospectiva de las principales tendencias de la economía mundial en una época en que la caída del Muro de Berlín hubiera parecido una fantasía y en la que ni siquiera se insinuaba todavía la glasnost. En ese ámbito ubicaba Laidlaw a las cooperativas y discurría acerca de su rol futuro, advirtiendo claramente que ellas formaban parte del nuevo mundo que se avecinaba con todos sus desafíos y sus oportunidades.

Dos libros posteriores se ubican en la misma línea, si bien ellos fueron publicados cuando ya la globalización era inminente o se hallaba instalada. El primero fue Los principios cooperativos hoy y mañana debido a la pluma de W.P. Watkins un ex director general de la $\mathrm{ACl}$ con extensa trayectoria en el cooperativismo británico y mundial². Allí brinda Watkins una visión aguda del nuevo contexto económico internacional dentro del cual el movimiento cooperativo habría de desenvolverse y con base en ella expone sus fundados puntos de vista acerca de los principios cooperativos como contribución a la revisión en la que se encontraba a la sazón empeñada la $\mathrm{ACl}$. El otro libro fue el resultado de una investigación especialmente encomendada por la $\mathrm{ACl}$ al estudioso del cooperativismo sueco Sven Aake Böök como consecuencia del XXIX Congreso realizado en Estocolmo en 1988, titulado Los valores cooperativos en un mundo cambiante ${ }^{3}$. En éste se realiza un amplio relevamiento a escala internacional de las corrientes de la actividad y el pensamiento del movimiento cooperativo cuando ya se había desatado el proceso globalizador y la $\mathrm{ACI}$ se había propuesto la tarea de definir los valores cooperativos en el nuevo marco mundial —cometido del XXX Congreso realizado en Tokio en 1992 - como paso previo a la reformulación de los principios cooperativos que habría de encarar el Congreso del Centenario a realizarse en Manchester en 1995.

1 Este documento fue motivo de numerosas ediciones en distintos idiomas. Una versión en español fue publicada por Intercoop, Buenos Aires, 1981.

2 Originalmente este libro fue publicado bajo el título Cooperative Principles: Today and Tomorrow, Holyoake Books, Manchester, 1986.

3 Cooperative Values in a Changing World, Internacional Cooperative Alliance, Geneva, 1992, cuya versión en español fue publicada por la Oficina Regional de la ACI de San José (Costa Rica) en el mismo año. 
Estos antecedentes culminan con la Declaración sobre la Identidad Cooperativa aprobada en el mencionado Congreso de Manchester ${ }^{4}$. Este breve documento, compuesto de tres partes: definición, valores y principios cooperativos, constituye la autoproclamación de la presencia cooperativa en el mundo globalizado manifestando su peculiar identidad juntamente con los rasgos que perfilan sus características y problemas actuales. Esta Declaración no fue, obviamente, el resultado de la deliberación de un congreso de unos pocos días de duración sino el punto final de un proceso de análisis y consulta de nivel mundial que abarcó todos los continentes y clases de cooperativas mediante una amplia discusión y una elaboración profunda que concluyó con un informe maduro para su tratamiento final en Manchester. La Declaración fue acompañada por un documento de referencia que contribuye a aclarar y precisar sus alcances facilitando su mejor comprensión.

Queda, de esta suerte, delineado el enfoque cooperativo de la globalización; es decir, cómo el movimiento cooperativo se percibe a sí mismo en ese contexto. Es la autorreflexión del cooperativismo en el mundo globalizado. A partir de ella corresponde reflejar al derecho cooperativo en el espejo de la globalización.

\section{El derecho en el mundo globalizado}

El derecho como fenómeno cultural globalizado no es una novedad, al menos en el mundo occidental donde el derecho romano constituyó durante siglos el derecho común, tanto bajo el Imperio como a lo largo de la Edad Media. Este fenómeno constituyó una de las características fundacionales de la cultura jurídica de Occidente que dejó hondamente impresa su huella hasta nuestros días.

Por otra parte, la lex mercatoria vino asimismo a constituir un derecho común de la actividad comercial vigente prácticamente sin fronteras a lo largo de varios siglos durante los cuales las costumbres mercantiles y la justicia ejercida por los propios comerciantes representó el derecho universal que regulaba el quehacer económico. A lo largo de todo este extenso período la aplicación de las normas regulatorias

4 La versión en español de este documento fue publicada por Intercoop bajo el título Los principios cooperativos para el siglo xxI, Buenos Aires, 1996. 
de esta actividad no se detenía en las fronteras de reinos o naciones y, por el contrario, se extendía sin reparar en límites geográficos ni políticos. Fue recién con el advenimiento de los estados nacionales modernos que comenzaron a ponerse vallas a esa extensión y a reivindicarse para ellos la exclusividad de la legislación y de la jurisdicción mercantil con lo que se atomizó la anterior amplitud global del derecho mercantil ${ }^{5}$.

Esta situación de exclusividad jurídica nacional — producto del nuevo orden político nacido con el mundo moderno- subsiste hasta la época actual, pese al surgimiento de una nueva realidad política tal como la integración regional que pugna por superar con sus atribuciones legislativas y jurisdiccionales la estrechez de los límites nacionales. No obstante, el fenómeno jurídico de la supranacionalidad es todavía incipiente $y$, por supuesto, descansa sobre la base de su aceptación por parte de los estados nacionales que continúan siendo los protagonistas de la escena política contemporánea.

Esos mismos estados, sin embargo, han ido promoviendo la internacionalización del derecho a través de acuerdos, tratados y convenciones que van en creciente aumento para regular numerosos aspectos del derecho privado, especialmente los vinculados con las transacciones económicas, de lo cual puede considerarse paradigmática la Convención de Viena de 1980 sobre compraventa internacional de mercaderías. Dentro de este campo resulta particularmente interesante destacar la tarea que cumplen los organismos internacionales gubernamentales encargados de promover tales acuerdos mediante estudios y tareas preparatorias orientadas a la elaboración de los respectivos proyectos. Así sucede con la UNCITRAL de las Naciones Unidas en el plano internacional y con las CIDIP en el ámbito americano ${ }^{6}$.

5 Este proceso se encuentra eficazmente tratado por Francesco GaLGANo en Historia del derecho mercantil, trad. de la 2. ${ }^{a}$ ed. italiana por Joaquín Bisbal, LAIA, Barcelona, 1981, passim.

6 La Comisión de las Naciones Unidas para el Derecho Mercantil Internacional (UNCITRAL) fue creada por Resolución 2205 de la Asamblea General de la ONU del 17.2.66 con mandato para realizar trabajos que promovieran la armonización y unificación progresiva del Derecho Mercantil internacional conforme los lineamientos establecidos por dicha resolución. Las Conferencias Interamericanas de Derecho Internacional Privado (CIDIP) son convocadas por la Asamblea General de la OEA y su preparación está a cargo del Comité Jurídico Interamericano, la Secretaría General y reuniones de expertos convocadas al efecto. 
De igual forma ocurre con los organismos internacionales constituidos por los gobiernos sin funciones específicamente relacionadas con la elaboración de normas sino vinculados con determinadas actividades (monetarias, financieras, comerciales o de otro orden), tales como el FMI, el Banco Mundial, la OMC, etc. Estos organismos - cuya existencia se multiplica de continuo para abarcar nuevos y diversos campos de actividad - van produciendo un repertorio de disposiciones y decisiones que configuran una nutrida trama que condiciona múltiples aspectos de las relaciones privadas internacionales.

Asimismo corresponde destacar la función que cumple UNIDROIT —organización intergubernamental independiente ${ }^{7}$ — especialmente en el terreno de la definición de los principios universales de los contratos comerciales. A través de su actividad ha ido promoviendo activamente diferentes mecanismos cuyo objeto consiste precisamente en generar y desarrollar un derecho (aunque no legislado) de ámbito global. Esa acción se cumple de manera sostenida e intensa a través de la búsqueda y definición de principios jurídicos universales aplicables a las relaciones entre particulares de distintos países y de sistemas jurídicos diversos. De esa manera, el contrato, instituto jurídico de fundamental importancia, viene a quedar perfilado dentro de lineamientos aplicables universalmente sin sujeción a ordenamientos nacionales determinados.

Paralelamente, el auge alcanzado por el arbitraje internacional en materia comercial en época reciente ha contribuido decididamente a promover la globalización del derecho no solamente por el recurso a organismos mundiales (y no nacionales) de resolución de conflictos (caso típico de la Cámara de Comercio Internacional) sino por cuanto estos organismos van conformando un repertorio de resoluciones que constituye verdadera jurisprudencia a la que se recurre para la solución de posteriores casos, tanto por parte de aquéllos como de otros organismos con funciones similares ${ }^{8}$.

Todo este complejo y diverso conjunto de fuentes jurídicas difusas - entre las cuales se advierte un notable retroceso de la legislación

7 El Instituto Internacional para la Unificación del Derecho Privado (UNIDROIT) tuvo su origen en la década de 1920 dentro de la órbita de la antigua Sociedad de las Naciones pero fue reorganizado en 1940 en base a un acuerdo multilateral.

8 Francesco Galgano, La globalización en el espejo del derecho, traducción de Horacio Roitman y María de la Colina, Rubinzal-Culzoni, Buenos Aires, 2005, pp. 81 y ss. 
con el correlativo auge de la jurisdicción y el contrato- lleva a que en nuestros días se hable de una nueva lex mercatoria similar a aquélla que en su hora originó la costumbre universal de los comerciantes, pero ahora con un alcance y profundidad mucho mayores.

\section{La globalidad del cooperativismo y de la legislación cooperativa}

El cooperativismo es global ${ }^{9}$. Si bien sus orígenes pueden ubicarse puntualmente en algunos países determinados según sus diversas manifestaciones concretas (cooperativas de consumo en Gran Bretaña; cooperativas agrarias y de crédito en Alemania; cooperativas de trabajo en Francia), lo cierto que sus caracteres fundamentales tienen presencia universal bajo sus diversas expresiones. Desde este punto de vista, la globalización no es un fenómeno nuevo para el cooperativismo, pues éste nació global y aun donde se originó en un transplante cultural (como sucedió en la India, por ejemplo) sus rasgos fueron desde el inicio comunes con los de las cooperativas de los otros países. La proclamación de los principios cooperativos por parte de la $\mathrm{ACl}$ constituye solamente una ratificación del carácter universal del cooperativismo; en rigor, no es que el movimiento cooperativo sea universal en virtud de la existencia de los principios cooperativos sino que por ser universal el cooperativismo existen los principios cooperativos.

El régimen legal surgido para regular a las cooperativas a partir de la ley inglesa de $1852^{10}$ asumió, por lo tanto, rasgos comunes en los diferentes países toda vez que el objeto o materia de la regulación era idéntica. La diferencia entre tales regímenes legales radicaba únicamente en las características propias del derecho de cada país según su peculiar tradición jurídico cultural. El derecho cooperativo comparado ilustra adecuadamente acerca de esta circunstancia ya a partir de las primeras leyes sancionadas en Europa Occidental y posteriormente se fue acentuando ese rasgo a medida que las nuevas legislaciones fueron tomando en cuenta a las precedentes.

9 Javier Divar afirma que «el cooperativismo también es global, por su esencia solidaria (no por la acumulativa, como en el caso del capitalismo) ...» (Globalización y democracia, Dykinson, Madrid, 2005, p. 79).

10 Laszlo VALKo, "The First Co-operative Law», Essays on Modern Cooperation, Washington State University Press, 1964, pp. 79 y ss. 
Con el tiempo la apuntada situación llevó a que en diferentes regiones o clases de cooperativas se promoviera la elaboración de leyes uniformes o «leyes modelo» sobre cooperativas que recogieron los rasgos comunes de estas entidades, incluso en países con sistemas jurídicos diferentes. Es arquetípico el caso de la Model Co-operative Societies Law preparada por el gobierno británico para sus colonias y que fue utilizada ampliamente en Asia y Africa ${ }^{11}$. De igual manera cabe mencionar el Proyecto de Ley Marco para las cooperativas de América Latina elaborado por la Organización de las Cooperativas de América (OCA) en la década de 1980 que sirvió de orientación para la actualización de las leyes de varios países de esa región ${ }^{12}$. En cuanto a modelo para una clase específica de cooperativas resulta relevante la Model Law for Credit Unions elaborada por el Consejo Mundial de Cooperativas de Ahorro y Crédito (WOCCU) ${ }^{13}$ de la cual existen varias ediciones que fueron utilizadas en diferentes países.

Otro factor que contribuyó eficazmente a la globalización del derecho cooperativo fue -y continúa siendo- la labor desarrollada por los organismos gubernamentales tanto regionales como internacionales que se han venido ocupando de las cooperativas. Entre ellos corresponde destacar a la OIT que desde sus mismos orígenes prestó especial atención a las cooperativas realizando numerosos estudios y proyectos de asistencia técnica en materia de legislación cooperativa. Las recomendaciones 127 de 1966 y 193 de 2002 sobre el desarrollo de las cooperativas, aprobadas por la asamblea de la OIT ${ }^{14}$, contienen importantes elementos de universalización del derecho cooperativo. Por su parte, la propia asamblea general de las Naciones Unidas aprobó

11 B.J. SURRIDGE and Margaret DigBY, A Manual for Co.operative Law and Practice, $3^{\text {rd }}$ edition, W. Heffer, Cambridge, 1967 pp. 120 y ss, donde se reproduce integramente el texto con comentarios de los autores.

12 Este documento se encuentra reproducido y comentado en José M. Montolío, Legislación cooperativa en América Latina. Situación, derecho comparado y proceso de armonización, Ministerio de Trabajo y Seguridad Social, Madrid, 1990, pp. 276 y ss.

13 World Council of Credit Unions, Model Law for Credit Unions, Madison, 2000, passim. También pueden mencionarse la Model Credit Union Act elaborada por la Credit Union National Association en 1986 para los distintos estados de Norte América (publicado por CUNA, Madison, 1987, con comentario) y la Model Act para los países caribeños producida por la Caribbean Confederation of Credit Unions (2nd edition, Christ Church, Barbados, 1987).

14 Las recomendaciones 127 y 193 versan sobre la promoción de las cooperativas, pero mientras la primera está básicamente referida a los países en vías de desarrollo, la segunda es de carácter general. 
diversas resoluciones relacionadas con las cooperativas que son portadoras de importantes referencias acerca de la legislación cooperativa, entre las cuales cabe destacar la resolución 56/114 de diciembre de 2001, cuyo anexo está dedicado a las pautas para la creación de un entorno favorable para el desarrollo de las cooperativas ${ }^{15}$. Por su parte la OEA durante muchos años realizó una destacada tarea de estudio y asistencia técnica en esta materia para los países del continente americano.

Universidades y centros de estudio de distintas partes del mundo también colaboraron en idéntico sentido y la misma $\mathrm{ACl}$ se interesó en el tema, al punto de que la resolución que aprobó la Declaración sobre la Identidad Cooperativa en el Congreso de Manchester insta a los gobiernos a basar en ella la legislación cooperativa y a establecer un marco legal que permita a las cooperativas operar como organizaciones independientes gestionadas por sus socios ${ }^{16}$. Por su parte, la asamblea general de la ACl celebrada en Seúl en 2001 aprobó una resolución sobre legislación y políticas públicas en materia de cooperativas en la que recomienda tener en cuenta unos amplios lineamientos de legislación cooperativa general que ella refiere ${ }^{17}$.

\section{El derecho cooperativo en el nuevo contexto}

La reflexión sobre el derecho cooperativo en el mundo globalizado debe necesariamente realizarse a partir de la Declaración sobre la Identidad Cooperativa que, como se vio, es el documento que concentra y resume la posición del cooperativismo en el contexto de la globalización. Ello es así toda vez que el derecho cooperativo constituye la expresión jurídica del cooperativismo; por lo tanto debe reflejar cabalmente esta realidad subyacente.

15 Resolución de la Asamblea General de la ONU sobre las cooperativas en el desarrollo social del 19.12.01.

16 Punto 6 a) y b) de la resolución de la asamblea general de la $\mathrm{ACl}$ acerca de la Declaración sobre la Identidad Cooperativa, Manchester 1995, en Los principios cooperativos para el Siglo XXI, cit., pp, 8-9.

17 Resolución sobre Política y Legislación Cooperativa en Revista de la Cooperación Internacional (edición en español a cargo de Intercoop, Buenos Aires), N. ${ }^{\circ}$ 1-2003, pp. 86-87. El texto de los lineamientos —elaborado por Hagen Henry- está reproducido en el N. ${ }^{\circ}$ 2-2001 de la misma Revista, pp. 67 y ss. Recientemente fue publicada una versión revisada de esos lineamientos: Hagen HENRY, Guidelines for Cooperative Legislation, second revised edition, OIT, Geneva, 2005, passim. 
La Declaración recoge los profundos cambios producidos tanto en el mundo industrializado como en los países en desarrollo y los países en transición. De allí la rotunda afirmación de la autonomía e independencia de las cooperativas ( $4{ }^{\circ}$ principio), lo cual resulta particularmente importante en dos frentes: en primer lugar ante los gobiernos, que en regímenes socialistas han tendido a considerarlas como parte del aparato de la economía centralmente planificada y en los países del tercer mundo como agencias de desarrollo sujetas a las directivas de las oficinas gubernamentales. Pero de igual manera sostiene la autonomía de las cooperativas en los países industrializados en orden a garantizar su efectiva consideración como organizaciones de autoayuda gestionadas por sus socios.

Aspecto de singular importancia es la afirmación de la presencia cooperativa sin discriminaciones raciales, políticas, religiosas, sociales o de género (1. er principio), lo cual implica una categórica expresión de sentido universalista que supera fronteras y barreras de toda clase. Esta clara vocación humanista del cooperativismo, ratificada por su espíritu democrático, viene a constituir una decidida ratificación de su sentido global.

Una evidencia reveladora de la comprensión de la economía del mundo globalizado es el reconocimiento de que las cooperativas pueden captar capital de fuentes externas, si bien bajo la condición de que aseguren el control por los socios, manteniendo inalterable su autonomía e independencia (4..$^{\circ}$ principio). Esta es probablemente una de las cuestiones que ha suscitado mayor controversia en el seno del movimiento cooperativo: si es posible que las cooperativas se desarrollen en un ambiente de creciente concentración económica, donde el acceso a los recursos financieros constituye uno de los problemas más difíciles de resolver para la supervivencia en un medio altamente competitivo. La solución de la Declaración brinda una herramienta susceptible de ser utilizada siempre que no se afecte la garantía del control democrático por los socios quienes, por otra parte, deben contribuir a la formación del capital de su cooperativa según establece el 3. er principio.

El énfasis puesto por la Declaración en el gobierno democrático de las cooperativas ( $2 .^{\circ}$ principio) reafirma el núcleo de la doctrina señalando que los socios participan activamente en la fijación de políticas y en la toma de decisiones, pero también puntualizando que los representantes que se elijan por ese medio son responsables ante los socios. Esta definición - que no hace sino persistir en la línea tradicional 
de los principios cooperativos - viene a señalar con precisión la posición de las cooperativas dentro de la problemática actual de la llamada corporate governance, especialmente puesta de relieve por la globalización. En el caso de las cooperativas la respuesta es clara: gobiernan los socios y la actividad de la cooperativa se orienta a la satisfacción de las necesidades de éstos, de suerte tal que el gobierno cooperativo no tiene otro sentido que satisfacer a los socios mediante el ejercicio de la democracia. Por lo tanto, son de orden secundario las cuestiones relativas a los sistemas de organización monista, dualista o de otro tipo en tanto se salvaguarde el sentido fundamental del gobierno democrático entendido como "un socio, un voto».

Sin embargo, la satisfacción de las necesidades y aspiraciones económicas, sociales y culturales de los socios - que constituye el sentido original de la organización cooperativa - se ha de compaginar con la promoción del desarrollo sostenible de su respectiva comunidad (7. ${ }^{\circ}$ principio), lo cual es de la naturaleza misma de las cooperativas como entidades abiertas y de duración indefinida. En época reciente ha venido ganando terreno el tema de la corporate social responsability que consiste en una autolimitación que las corporaciones se imponen a su afán de lucro a fin de evitar excesos que resulten contraproducentes; en el caso de las cooperativas, en cambio, la preocupación por la comunidad es consistente con sus propios objetivos puesto que la promoción del desarrollo comunitario implica la promoción de sus socios y viceversa.

La Declaración sobre la Identidad Cooperativa coloca decididamente a las cooperativas en el mundo globalizado manteniendo la esencia que las caracteriza. Empero, la globalización económica y su correlato de globalización jurídica pretenden imponer un rasero que iguala a todas las organizaciones que actúan en el mercado sin tomar en consideración sus rasgos propios. La cuestión que se plantea, pues, es la siguiente: ¿es posible mantener y afirmar la identidad cooperativa en un mundo globalizado? ¿o las cooperativas están condenadas a mimetizarse, sea voluntaria o forzosamente, con las empresas comunes del mercado? La Declaración abre un horizonte de fundada esperanza para que el derecho cooperativo pueda afirmar la viabilidad de organizaciones económicas independientes gestionadas por sus socios para satisfacer sus necesidades y promover a sus comunidades. 